\title{
Un método para el tratamiento de las pilas y baterías domésticas usadas de tamaño medio III Parte. Propuesta de un método para su tratamiento ${ }^{(\bullet)}$
}

\author{
D. de Juan ${ }^{(*)}$, V. Meseguer ${ }^{(*)}$, A. Perales ${ }^{(*)}$ y L.J. Lozano ${ }^{(*)}$ \\ Resumen Se propone un método para llevar a cabo el tratamiento primario de las pilas y baterías domésticas \\ usadas. Se desarrollan los procesos necesarios para realizar el tratamiento secundario, recuperar los \\ metales contenidos y separar los componentes tóxicos de los residuos. En el tratamiento primario se \\ recupera el hierro directamente como una chatarra férrea. El cinc se recupera de la disolución \\ amoniacal procedente del tratamiento primario mediante un proceso hidrotermal. Para la \\ recuperación del cadmio, cobre y níquel se propone su cementación con polvo de cinc y posterior \\ aplicación del proceso COCADEX. La eliminación de los productos tóxicos de la fracción bióxido \\ resultante, así como la recuperación del mercurio se realizan mediante calcinación a $300-400{ }^{\circ} \mathrm{C}$. \\ El residuo de calcinación y la fracción no férrea se pueden tratar conjuntamente en un horno Waelz \\ para recuperar simultáneamente el cinc y el cadmio residual como óxido Waelz.
}

Palabras clave: Tratamiento de residuos. Pilas eléctricas. Metalurgia extractiva. Residuos sólidos. Recuperación de metales.

\section{A method for the processing of medium size used domestic cells and batteries}

Part. 3. Proposal of a method for their treatment

\begin{abstract}
A method for the primary treatment of spent batteries and domestic cells is proposed. Basic processes for the secondary treatment, metals recovering and detoxifying wastes are developed. Iron is directly recovered in the primary treatment as a ferrous scrap. Zinc is recovered from ammoniacal solution obtained in primary treatment by means of a hydrothermal process. For recovering cadmium, copper and nickel, a cementation with zinc dusts is proposed along with the application of the COCADEX process. Detoxifying the fraction bioxide obtained and the mercury recovered are made by heat treatment at 300 $400^{\circ} \mathrm{C}$. The heat treatment wastes and the non ferrous fraction can be treated in a Waelz furnace, for the simultaneous recovery of zinc and cadmium contained in the waste as a Waelz oxide.
\end{abstract}

Keywords: Treatment of wastes. Electric cells and batteries. Extractive metallurgy. Solid wastes. Metals recovery.

\section{INTRODUCCIÓN}

En la primera parte del trabajo desarrollado (I Parte), se puso de manifiesto la necesidad, tanto por razones económicas como medioambientales, de tratar las pilas y baterías domésticas usadas. Con ello se conseguiría minimizar el impacto nocivo

(•) Trabajo recibido el día 14 de junio de 1995. La I y II partes de este trabajo se publicaron en Rev. Metal. Madrid, 32 (1) y 32 (2), 1996, respectivamente.

(*) Grupo de Investigación INQUICA. Dpto. de Ingeniería Química Cartagena. Escuela Politécnica Superior de Cartagena. Universidad de Murcia. Paseo Alfonso XIII, 34. 30203-Cartagena, Murcia (España). que el vertido indiscriminado de estos materiales puede ejercer sobre el medioambiente, así como recuperar una serie de compuestos (fundamentalmente chatarra de hierro, cinc, níquel, cobre, cadmio y mercurio) con un valor potencial de $340 \cdot 10^{6}$ PTA/año.

Por ello, se llevó a cabo el tratamiento primario de las pilas y baterías domésticas usadas, siguiendo dos procedimientos diferentes: lixiviación ácida y lixiviación alcalina (II Parte). En este trabajo se comprobó que los mejores resultados se alcanzan cuando se sigue la lixiviación de tipo alcalino.

Teniendo en cuenta lo expuesto, a continuación se propone un método que permite procesar las pilas 
y baterías domésticas usadas. Puesto que en este tratamiento se obtienen diferentes fracciones con características muy diversas, se discute el destino final o el sistema a seguir para tratar dichas fracciones, en función de su composición y características.

\section{MÉTODO PRIMARIO DE TRATAMIENTO DE LAS PILAS Y BATERÍAS DOMÉSTICAS USADAS}

Con los resultados obtenidos en el trabajo previo (II Parte), se propone como método de tratamiento de las pilas y baterías domésticas usadas el proceso representado en la figura 1. A partir de este proceso se obtendrían los siguientes productos:

- Lejía, de la que se recuperarían cinc, cobre, cadmio y níquel, eliminándose el cloro en una purga controlada.

- Bióxido, cuyo destino final se tratará posteriormente en función del proceso de separación de los componentes tóxicos presentes y de la posible recuperación del cinc y cadmio. El peso de los bióxidos (ver Fig. 6, II Parte) es aproximadamente el $40 \%$ del correspondiente a las pilas.

- Chatarra férrea, que se vendería como tal, y cuyo peso supone un $15 \%$ del original.

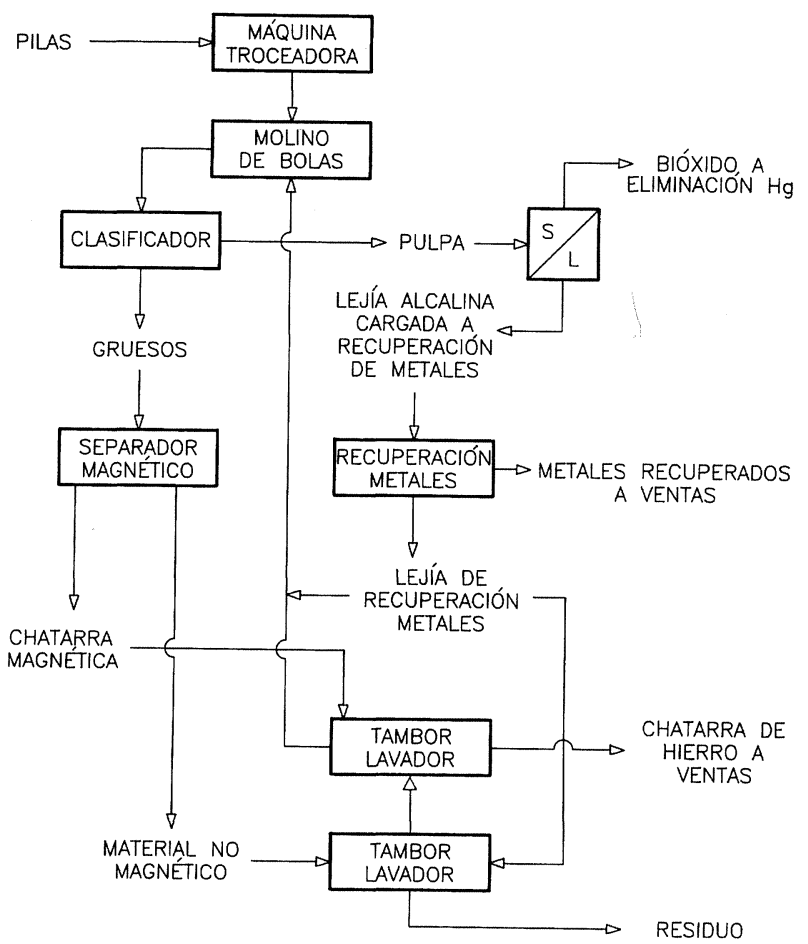

FIG. 1.- Esquema básico para el tratamiento de las pilas y baterías domésticas usadas.

FIG. 1.- Basic flow sheet for treatment of spent batteries.
- Residuo, cuyo destino es elegible y del cual se hablará posteriormente. $\mathrm{Su}$ peso es un $18 \%$ del inicial.

\section{MÉTODOS DE TRATAMIENTO SECUNDARIO DE LOS PRODUCTOS PROCEDENTES DEL TRATAMIENTO PRIMARIO DE LAS PILAS Y BATERÍAS DOMÉSTICAS USADAS}

Está claro que el método de tratamiento de las pilas y baterías domésticas usadas no quedaría definido si no se completara el método primario con la descripción de todos los procesos necesarios que permitan valorar los productos obtenidos, los cuales deberán tener un bajo contenido de componentes tóxicos.

\subsection{Tratamiento de recuperación de los metales solubilizados en la lejía}

Una vez disueltos los diversos metales en la lejía, fundamentalmente el cinc, es preciso proceder a su recuperación, a ser posible en el estado de máximo valor añadido.

La forma de realizar la recuperación del cinc de las disoluciones amoniacales es conocida de antiguo, aplicándose con éxito comercial a la recuperación del níquel (1). El método consiste en la precipitación hidrotermal de un carbonato básico de cinc, tras la eliminación del amoniaco libre de la disolución amonio-amoniacal.

Para conseguir un producto de cinc con alto valor comercial es preciso que la disolución alimentada a la etapa de neutralización tenga la pureza suficiente para que el carbonato básico de cinc obtenido pueda ser transformado en otro producto, metal, óxido o sal, que responda a las especificaciones existentes en el mercado. Será necesario, por tanto, purificar la disolución procedente de la etapa de tratamiento primario.

Por otra parte, es preciso recuperar los metales minoritarios con interés económico existentes en la disolución, que son fundamentalmente cobre, cadmio y níquel.

Ambas operaciones, purificación y preconcentración de minoritarios, se realizan por cementación con polvo de cinc. El cemento obtenido se puede tratar por el proceso COCADEX ( 2 y 3 ), que permite la recuperación selectiva de estos metales a partir de cementos metálicos al estado de máximo valor añadido, metal o sal.

Es decir, la conjunción de una etapa de purificación con el proceso COCADEX permite: 
- Depurar la lejía alcalina de cinc.

- Recuperar el cobre, el cadmio y el níquel separadamente.

En el caso de que la cantidad de cemento producida no aconsejara realizar la inversión necesaria para incorporar el proceso COCADEX al tratamiento global de las pilas, este producto se podría vender o entregar a los productores de cadmio, cobre o níquel, con lo que se eliminaría su posible impacto ambiental.

La lejía de cinc purificada se envía a la etapa de precipitación hidrotermal del carbonato básico de cinc.

Una vez separado el carbonato básico de cinc se presentan varias opciones:

- Disolución en ácido sulfúrico diluido y electrólisis del sulfato de cinc formado para obtener cinc metal, que se incorporaría al ciclo de metal de primera fusión.

- Calcinación del carbonato básico, con el fin de obtener óxido de cinc que es posible vender para alimentación animal (como oligoelemento), carga de neumáticos, industria cerámica, etc.

- Transformación en cualquier otra sal de cinc, como sulfato (industria minera), cloruro (industria metalúrgica), etc.

El proceso de recuperación de los metales contenidos en la lejía se esquematiza en la figura 2.

Hay que significar que, una vez realizada la recuperación de los metales, se debe efectuar una purga controlada con el fin de eliminar los cloruros contenidos en la disolución alcalina. Antes de proceder a su vertido se debe llevar a cabo su corrección.

El principal problema que podría presentar este proceso es la recuperación del amoniaco, inconveniente que viene paliado por el hecho de que la materia prima aporta una cierta cantidad de ion amonio en su composición.

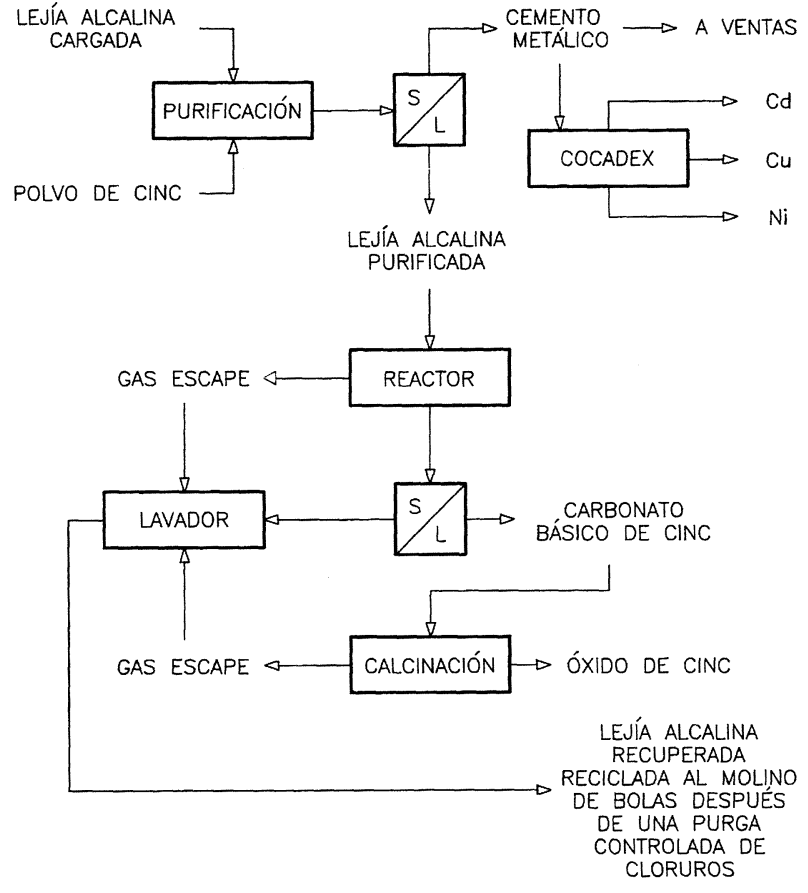

FIG. 2.- Esquema básico para la recuperación de metales y de la lejía de ataque.

FIG. 2.- Basic flow sheet for metals and leaching solution recovery.

\subsection{Separación de los componentes tóxicos de la fracción bióxido}

\subsubsection{Planteamiento inicial}

Tal como se ha diseñado el proceso principal, el producto bióxido es la suma de las dos fracciones obtenidas en los ensayos previos. Su composición elemental se recoge en la tabla I.

Este producto posee una elevada cantidad de cinc, aproximadamente un $28 \%$ del contenido de las pilas, por lo que, además de eliminar los componentes tóxicos, puede ser interesante recuperar dicho metal.

Por otra parte, el elevado contenido de mercurio, superior a los $300 \mathrm{~g} / \mathrm{t}$, no aconseja su vertido directo.

TABLA I.- Análisis químico elemental del producto bióxido, \%

TABLE I.-Elemental chemical analysis from product bioxide, \%

\begin{tabular}{|l|c|c|c|c|c|c|c|c|}
\hline Producto & $\begin{array}{c}\text { Peso } \\
\text { inicial, } \\
\%(*)\end{array}$ & $\mathrm{Zn}$ & $\mathrm{Fe}$ & $\mathrm{Cu}$ & $\mathrm{Cd}$ & $\mathrm{Ni}$ & $\mathrm{Mn}$ & $\mathrm{Hg}$ \\
\hline Bióxido 1 & 31,5 & 18,3 & 3,1 & 0,10 & 0,24 & 0,25 & 33,8 & 0,0293 \\
\hline Bióxido 2 & 8,6 & 9,3 & 6,1 & 0,13 & 0,17 & 0,25 & 24,7 & 0,0446 \\
\hline Bióxido & 40,1 & 16,4 & 3,7 & 0,11 & 0,23 & 0,25 & 31,9 & 0,0326 \\
\hline
\end{tabular}

(*) Tanto por ciento respecto a la masa total de pilas. 
Teniendo en cuenta ambas premisas parece conveniente realizar su tratamiento con dos fines:

- Recuperar el cinc y los minoritarios que sea posible.

- Eliminar los componentes tóxicos y/o inertizar.

Los ensayos de solubilidad, vía agente ácido, permiten indicar que este tratamiento no sería el idóneo para alcanzar los fines perseguidos, ya que:

- Se producirían lejías con alto contenido de manganeso, lo que introduciría problemas a la hora de su eliminación o vertido.

- El mercurio no se eliminaría totalmente del producto bióxido, ya que este elemento se reparte entre la lejía y el producto sólido. Esto traería consigo extender el problema a las diferentes fracciones resultantes, puesto que sería preciso desmercurizarlas antes de enviarlas a su destino final.

Las consideraciones anteriores llevaron a estudiar la posibilidad de eliminar el mercurio por vía térmica, por lo que se ensayó el comportamiento del producto bióxido frente a un tratamiento térmico.

\subsubsection{Comportamiento térmico de la fracción bióxido de manganeso}

Para llevar a cabo los ensayos de calcinación de los bióxidos se colocaron muestras de los mismos en un horno a temperatura ambiente. Se comenzó el calentamiento a una velocidad de $5{ }^{\circ} \mathrm{C} / \mathrm{min}$. Al alcanzar la temperatura de ensayo, ésta se mantuvo durante 1 h. A continuación, se retiró la muestra y se dejó enfriar en un desecador con gel de sílice. En el calcinado así obtenido, se determinó la pérdida de peso por calcinación y el mercurio residual. Los resultados se presentan en las figuras 3 y 4 .

En la figura 3 se puede apreciar que la calcinación se produce en dos etapas. En la primera, hasta los $400{ }^{\circ} \mathrm{C}$, existe un marcado incremento de la pérdida por calcinación con la temperatura. Posteriormente, la pérdida de peso es más lenta, hasta alcanzar valores próximos al $30 \%$ a $900{ }^{\circ} \mathrm{C}$. En la primera etapa se debe producir la pirólisis de los productos de tipo orgánico, mientras que en la segunda etapa tiene lugar la combustión del residuo carbonoso y la descomposición de las sustancias de tipo inorgánico.

En la figura 4 se observa que la eliminación del mercurio tiene lugar fundamentalmente durante la primera etapa, hasta los $300{ }^{\circ} \mathrm{C}$, temperatura a la cual se ha eliminado más del $90 \%$ del mercurio contenido en las muestras.

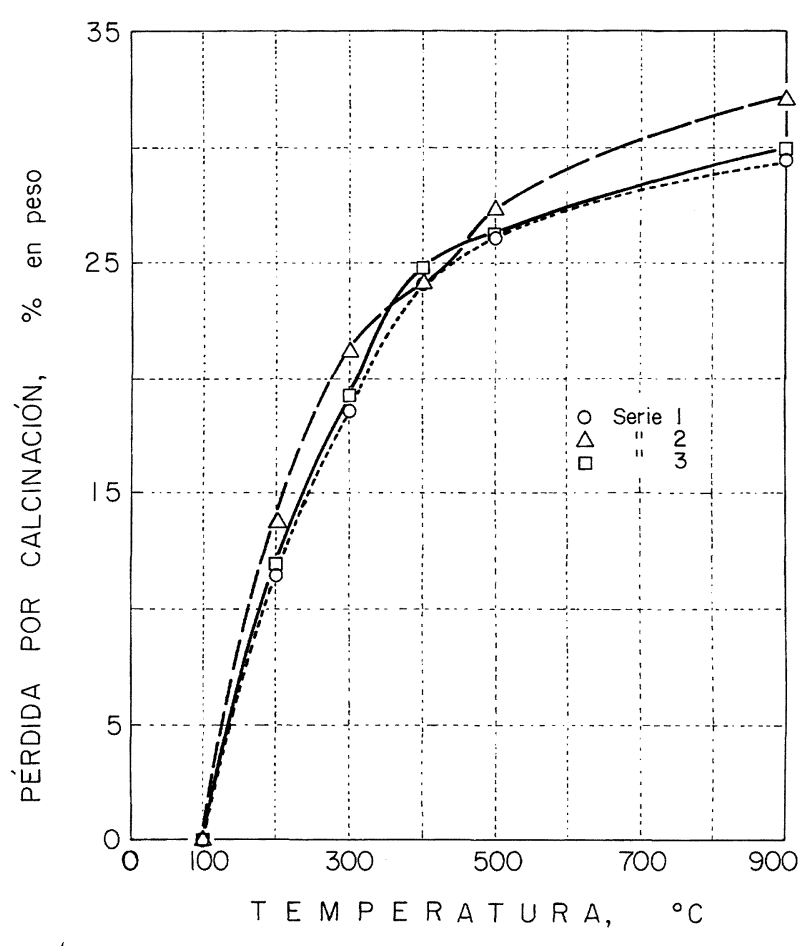

FIG. 3.- Efecto de la temperatura en la pérdida de peso por calcinación de los bióxidos.

FIG. 3.- Effect of temperature in weight losses by heating of bioxides.

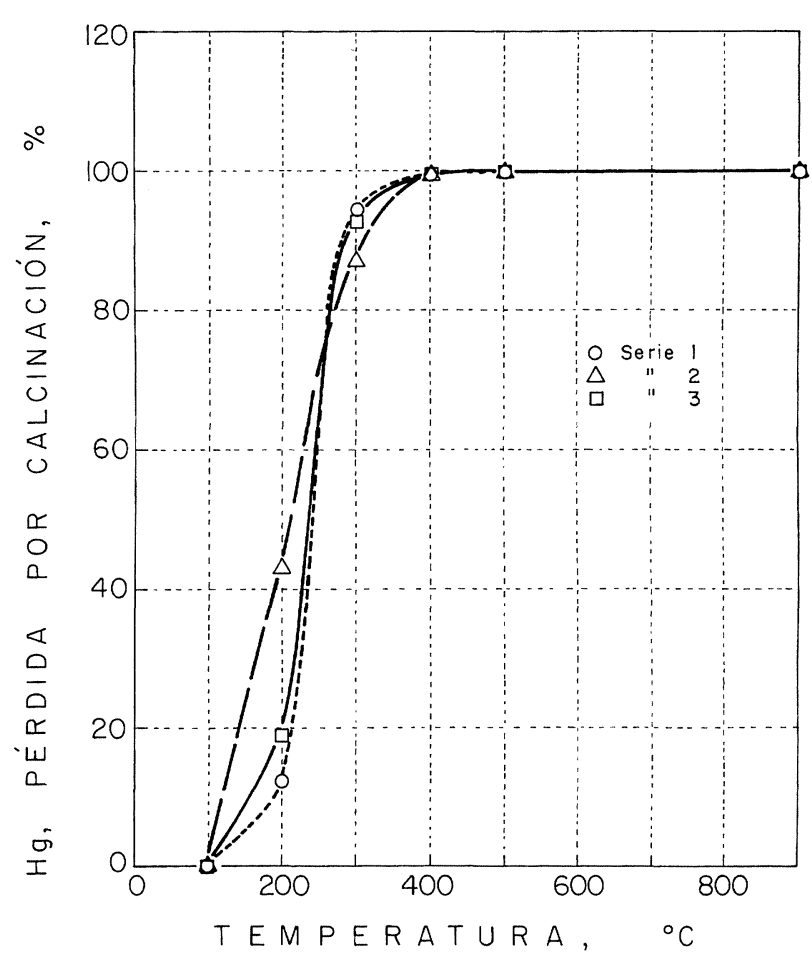

FIG. 4.- Efecto de la temperatura en la eliminación de mercurio en la calcinación de los bióxidos.

FIG. 4.- Effect of temperature in mercury removal by heating from bioxides. 


\subsubsection{Propuesta de un método para el tratamiento de la fracción bióxido}

De acuerdo con los resultados recogidos en los ensayos de calcinación sería previsible que en la calcinación del producto bióxido a $300{ }^{\circ} \mathrm{C}$ se obtuviera, por una parte, el mercurio a partir de su condensación de los gases de escape, y por otra, un sólido residual desmercurizado.

Operando de esta forma se podría:

- Recuperar entre el 85 y el $90 \%$ del mercurio contenido en las pilas, al estado de mercurio metal.

- Obtener un residuo calcinado que supondría el 30-35\% del peso inicial de las pilas, y cuya composición sería la que se muestra en la tabla II. Este producto, dado su alto contenido en cinc, podría tratarse en un horno Waelz conjuntamente con los polvos volantes de aceria. De esta forma se conseguiría recuperar el resto del cinc y del cadmio, mientras que los otros metales irían a una escoria inerte que podría utilizarse como relleno.

En una variante del esquema propuesto, el residuo procedente del tratamiento primario de las pilas se podría mezclar con el residuo de calcinación del bióxido, para después aplicar el proceso Waelz al conjunto, tal y como se muestra en la figura 5. Con ello, el único residuo a que daría lugar el tratamiento de las pilas sería la escoria Waelz.

En esta variante podría surgir alguna complicación debido a que en la pirólisis de los plásticos presentes en las pilas se podría generar ácido clorhídrico, aunque la cantidad de ácido producido sería mínima dado el alto porcentaje de cloro presente en los polvos volantes de acería.

De todas formas, el tratamiento térmico conjunto de ambos productos procedentes del procesado primario de las pilas debería ensayarse una vez en marcha la instalación en donde se llevara a cabo este tratamiento primario.

TABLA II.- Composición química elemental teórica de la fracción bióxido calcinada, \%

TABLE II.- Estimated elemental chemical composition from calcinated bioxide fraction, $\%$

\begin{tabular}{|l|c|ccccccc|}
\hline & $\begin{array}{c}\text { Peso } \\
\text { inicial, } \\
\%(*)\end{array}$ & $\mathrm{Zn}$ & $\mathrm{Fe}$ & $\mathrm{Cu}$ & $\mathrm{Cd}$ & $\mathrm{Ni}$ & $\mathrm{Mn}$ & $\mathrm{Hg}$ \\
\hline $\begin{array}{l}\text { Calcinado } \\
\text { a } 300^{\circ} \mathrm{C}\end{array}$ & 32,3 & 20,3 & 4,6 & 0,13 & 0,28 & 0,31 & 49,5 & 0,0002 \\
\hline
\end{tabular}

(*) Tanto por ciento respecto a la masa total de pilas.

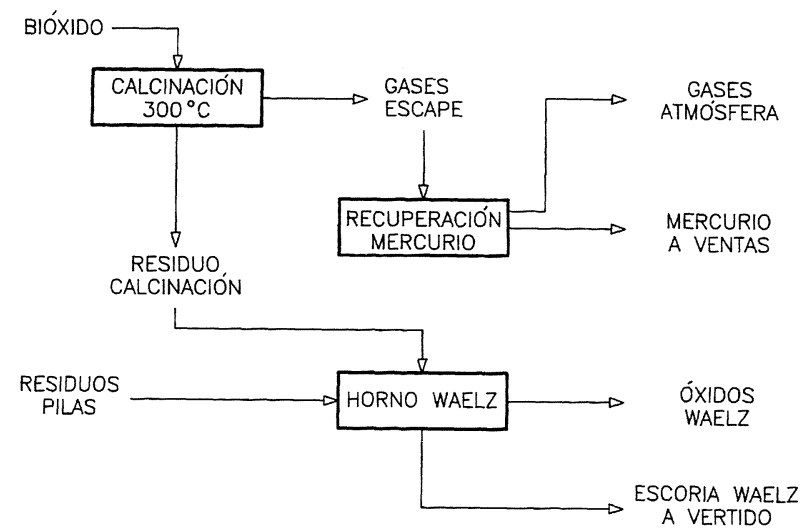

FIG. 5.- Esquema del tratamiento de desmercurización y recuperación de cinc en los bióxidos.

FIG. 5.- Flow sheet for mercury elimination and zinc recovery from bioxides.

\subsection{Chatarra férrea}

Este producto, por su composición, se puede comercializar directamente sin necesidad de someterlo a un tratamiento posterior.

\subsection{Residuo}

Puesto que tanto la chatarra no férrea como los plásticos no presentan característica alguna que los haga apetecibles comercialmente, parece conveniente unirlos en un solo producto residual del tratamiento primario. La composición de este producto, residuo del tratamiento primario, se presenta en la tabla III. La composición de este residuo ofrece una doble posibilidad en cuanto a su manejo.

La primera posibilidad es la que se indica en el apartado anterior, es decir, su tratamiento conjunto con el residuo de calcinación del producto bióxido. La composición de esta posible mezcla se muestra en la tabla IV.

La segunda opción consiste en proceder a su vertido directo, en vertedero controlado, teniendo en cuenta el bajo peso residual que supone, del orden de un $18 \%$ sobre el peso inicial de las pilas, y su bajo contenido metálico.

\section{PROPUESTA DE OPCIONES PARA EL TRATAMIENTO GLOBAL DE LAS PILAS Y BATERÍAS DOMÉSTICAS USADAS}

A la vista de los resultados obtenidos y de todo lo expuesto anteriormente, para el tratamiento global de las pilas y baterías domésticas usadas se puede proponer el esquema simplificado de la figura 6. En el mismo se aprecia que, en el tratamiento primario de las pilas y baterías agotadas, se pueden obtener los siguientes productos: 
TABla III.- Composición teórica elemental del producto residual obtenido en el tratamiento primario de las pilas, $\%$

TABLE III.- Estimated elemental composition from waste product obtained in the primary treatment of batteries, \%

\begin{tabular}{|c|c|c|c|c|c|c|c|c|c|}
\hline \multicolumn{2}{|c|}{ Producto } & $\begin{array}{c}\text { Peso } \\
\text { inicial, } \\
\%(*)\end{array}$ & $\mathrm{Zn}$ & $\mathrm{Fe}$ & $\mathrm{Cu}$ & $\mathrm{Cd}$ & $\mathrm{Ni}$ & $\mathrm{Mn}$ & $\mathrm{Hg}$ \\
\hline \multicolumn{2}{|c|}{$\begin{array}{l}\text { No férreos } \\
(* *)\end{array}$} & 13.96 & 1.7 & 0.7 & 0.50 & 0.02 & 0.06 & 5.23 & 0.011 \\
\hline \multicolumn{2}{|c|}{$\begin{array}{l}\text { Plásticos } \\
(* * *)\end{array}$} & 4.03 & 5.4 & 2.0 & 0.13 & 0.07 & 0.12 & $\begin{array}{c}12.3 \\
6\end{array}$ & 0.001 \\
\hline \multicolumn{2}{|c|}{$\begin{array}{l}\text { Residuo } \\
\text { total }\end{array}$} & 17.99 & 2.5 & 1.0 & 0.42 & 0.03 & 0.07 & 6.83 & 0.0087 \\
\hline \multicolumn{10}{|c|}{ (*) Tanto por ciento respecto a la masa total de pilas. } \\
\hline \multicolumn{10}{|l|}{$(* *)$} \\
\hline$(* * *)$ & $\begin{array}{l}\text { La sun } \\
\text { mente } \\
\text { rial pu }\end{array}$ & a total de & & elemer & entos in & adicado & os supo & ne apr & $\begin{array}{l}\text { oximada- } \\
\text { del mate- }\end{array}$ \\
\hline
\end{tabular}

TABLA IV.- Análisis químico elemental de la posible alimentación al proceso Waelz, $\%$

TABLE IV.- Elemental chemical analysis from probable feeding on Waelz process, $\%$

\begin{tabular}{|l|c|c|c|c|c|c|c|c|}
\hline Producto & $\begin{array}{c}\text { Peso } \\
\text { inicial, } \\
\%(*)\end{array}$ & $\mathrm{Zn}$ & $\mathrm{Fe}$ & $\mathrm{Cu}$ & $\mathrm{Cd}$ & $\mathrm{Ni}$ & $\mathrm{Mn}$ & $\mathrm{Hg}$ \\
\hline $\begin{array}{l}\text { Residuo } \\
\text { pilas }\end{array}$ & 17,99 & 2,5 & 1,0 & 0,42 & 0,03 & 0,07 & 6,83 & 0,0087 \\
\hline $\begin{array}{l}\text { Bióxido } \\
\text { calcinado }\end{array}$ & 29,13 & 20,3 & 4,6 & 0,13 & 0,28 & 0,31 & 39,45 & 0,0002 \\
\hline $\begin{array}{l}\text { Media } \\
\text { residuo } \\
\text { total }\end{array}$ & 50,32 & 13,93 & 3,32 & 0,23 & 0,19 & 0,22 & 27,78 & 0,0032 \\
\hline
\end{tabular}

(*) Tanto por ciento respecto a la masa total de pilas.

- Chatarra férrea (a ventas).

- Bióxido de manganeso (a vertido o tratamiento).

- Residuo (a vertido o tratamiento).

- Cemento metálico (a ventas).

- Óxido de cinc, cinc metal o sal de cinc (a ventas). En un tratamiento intermedio, se podría tratar la fracción bióxido, con lo que se producirían:

- Bióxido de manganeso calcinado (a tratamiento o vertido).

- Mercurio (a ventas).

En un tratamiento integrado de todas las fracciones producidas en el procesado primario de las pilas y baterías domésticas usadas, se podrían conseguir los siguientes productos:

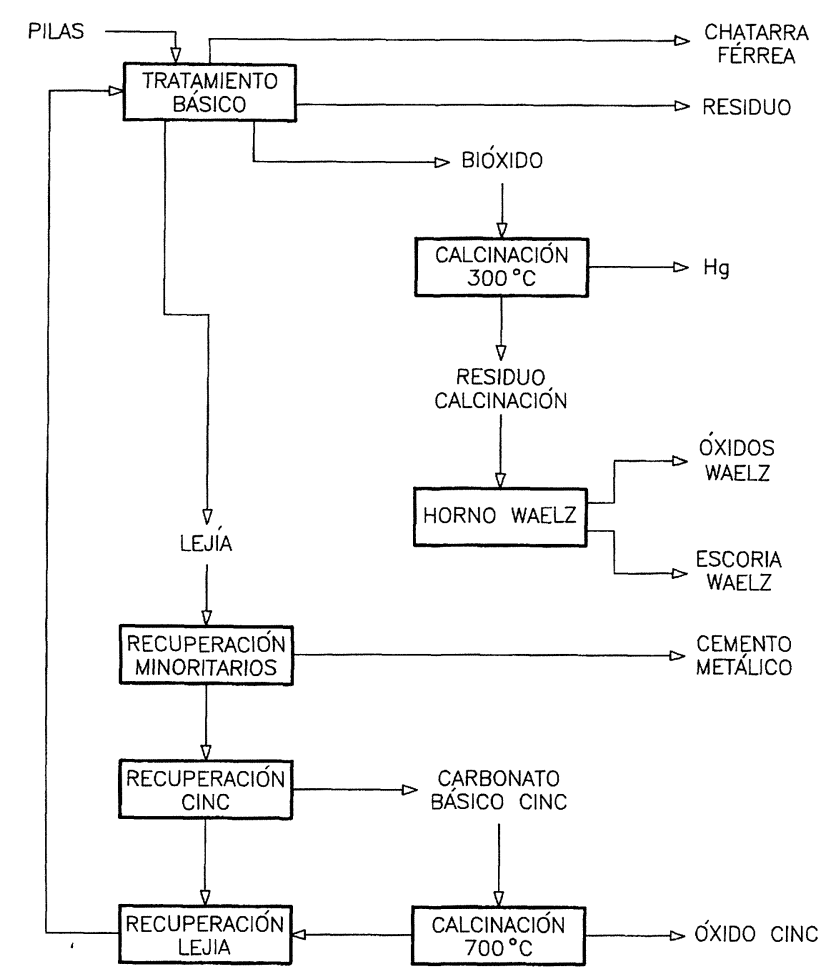

FIG. 6.- Esquema general para el tratamiento de pilas y baterías usadas, con indicación del método de recuperación e inertización.

FIG. 6.- General flow sheet for the treatment of spent batteries, with recovery and inert method's indication.

- De tipo comercializable:

- Chatarra férrea.

- Mercurio.

- Cemento metálico.

- Óxido de cinc, cinc metal o sal de cinc.

- De bajo valor comercial:

- Escoria Waelz.

- Productos de neutralización de la purga controlada.

De esta forma, es posible transformar las pilas y baterías agotadas en materiales y productos con un determinado valor comercial y con una mínima repercusión sobre el medio ambiente, con lo que se alcanzan los propósitos marcados al inicio de este trabajo.

\section{CONCLUSIONES}

A la luz de los resultados del trabajo realizado, se puede indicar que en España se consumen aproximadamente $310 \cdot 10^{6}$ unidades de pilas y baterías domésticas de tamaño medio al año (valor promedio para los años 1992 y 1993, sin considerar las pilas botón). El tratamiento de este material eliminaría o minimizaría el impacto nocivo que puede 
generar su vertido y, simultáneamente, permitiría recuperar una serie de materias primas no renovables con un valor potencial de, aproximadamente, $340 \cdot 10^{6}$ PTA/año.

Por ello se planteó inicialmente un esquema general del proceso para llevar a cabo el tratamiento primario de las pilas y baterías domésticas usadas, en el cual se combinan técnicas de concentración e hidrometalúrgicas. En dicho proceso se incluye una etapa de lixiviación, la cual se realizó de dos formas diferentes:

- Lixiviación ácida: Con ácido sulfúrico 1:4 y manteniendo el pH en 2.

- Lixiviación alcalina: Con una disolución 2,5M en carbonato amónico y cuyo $\mathrm{pH}$ se llevaba a 10,2 por adición de $\mathrm{NH}_{3}$ al $25 \%$.

Se comprobó que los mejores resultados se lograban cuando se empleaba la lixiviación alcalina, con lo que se obtenía:

- Una lejía que, a diferencia de lo que ocurre con la lejía procedente del tratamiento ácido, está prácticamente exenta de hierro, de mercurio y de manganeso. La lejía posee un elevado contenido en cloro, por lo que se deberán realizar purgas controladas. Tiene una concentración de cinc elevada y pequeños porcentajes de otros elementos minoritarios $(\mathrm{Ni}, \mathrm{Cd} \mathrm{y} \mathrm{Cu})$.

- Una fracción bióxido rica en cinc y manganeso.

- Una chatarra férrea, formada fundamentalmente por hierro y con un contenido apreciable de níquel y cadmio.

- Una chatarra no férrea de bajo contenido metálico.

- Una fracción papel+plásticos.

A partir de los resultados obtenidos en el tratamiento primario de las pilas usadas, se ha desarrollado un método para procesar estos materiales. En el mismo se incluyen los tratamientos a los que se deben someter las fracciones resultantes del tratamiento primario para conseguir su valoración o la reducción de los componentes tóxicos presentes.

A partir de la lejía de lixiviación, previamente purificada, se puede recuperar el cinc como carbonato básico de cinc mediante precipitación hidrotermal. Del cemento obtenido en el proceso de purifi- cación de la lejía es posible recuperar el cobre, cadmio y níquel individualmente, por aplicación del proceso COCADEX.

La calcinación a $300{ }^{\circ} \mathrm{C}$ de la fración bióxido, permitiría recuperar el $85-90 \%$ del mercurioo contenido en las pilas, así como obtener un residuo de calcinación rico en cinc que se podría tratar en hornos Waelz al objeto de recuperar el cinc y el cadmio presentes.

La chatarra férrea se puede comercializar directamente, sin tratamiento alguno.

La chatarra no férrea y la fracción plásticos+ papel se pueden tratar conjuntamente con el residuo de calcinación de la fracción bióxido, o bien, realizar su vertido directo en vertedero controlado.

De esta forma, la aplicación del tratamiento propuesto permitiría disminuir drásticamente la repercusión que el vertido de las pilas y baterías domésticas usadas puede ejercer sobre el medio ambiente, así como recuperar una serie de productos con un cierto valor comercial (chatarra férrea, mercurio, cemento metálico y cinc).

\section{Agradecimiento}

Los autores desean expresar su agradecimiento a la Fundación FREMAP por la concesión de una beca de investigación, gracias a la cual ha sido posible la realización de este trabajo.

\section{REFERENCIAS}

1) Hewedi, M.A y Engle, L.F. The $\mathrm{NH}_{3}-\mathrm{CO}_{2}-\mathrm{H}_{2} \mathrm{O}$ System at Atmospheric Pressure in non Ferrous Extractive Metallurgy. Intern. Symp. on Hydrometallurgy. American Institute of Mining, Metallurgical \& Petroleum Engineers. Chicago. 1973.

2) Perales Agüera, A. Estudio técnico-económico de un método de tratamiento no contaminante de los residuos de purificación en la hidrometalurgia del cinc. Tesis doctoral. Univ. de Murcia. 1993.

3) DE JuAn, D. y Perales, A. Ecological treatment of waste products from zinc hydrometallurgy. Proc. Intern. Symp. Hydrometallurgy'94. Institution of Mining and Metallurgy and the Society of Chemical Industry. Cambridge. 1994. 